Remenova, K., Jankelova, N. (2019). How Successfully can Decision-Making Style Predict the Orientation toward Well- or Ill-Structured Decision-Making Problems. Journal of Competitiveness, 11(1), 99-115. https://doi.org/10.7441/joc.2019.01.07

\title{
HOW SUCCESSFULLY CAN DECISION-MAKING STYLE PREDICT THE ORIENTATION TOWARD WELL- OR ILL-STRUCTURED DECISION-MAKING PROBLEMS
}

\section{- Katarina Remenova, Nadezda Jankelova}

\begin{abstract}
A decision-making style is the manner through which a manager acquires, processes and uses information in the decision-making process. It is a set of qualitative indicators which within the decision-making process manifest themselves in the form of a decision-making style and is a typical method of implementing a decision. Knowledge of decision-making styles and their active use in a management structure contributes directly to building the competitiveness of the business. Identifying decision-making styles and delegating the right decision tasks to the right employee who possesses the fundamental knowledge to address a particular type of decisionmaking problem (well or poorly structured) is the essence of competent decision-making. This research paper deals with the relationship between the decision-making style of a manager in terms of the type of decision-making problems. Binary logistic regression was used to predict the relationship between the type of decision problem (binary dependent variable) and the overall score in the decision-making style (cardinal independent variable) through which the probability of the occurrence of the dependent value was calculated. Based on these results, we assert that as the unit score in the intuitive decision-making style increases, the odds ratio in a group of ill-structured decision-making problems increases as well. The prediction for the growth of the Sensing and Thinking odds ratio has not been confirmed. Results of non-parametric testing using the Mann Whitney $\mathrm{U}$ test confirmed that the preference for the type of decision-making problem has a statistically significant effect on the score achieved in the Sensing and Intuiting decision-making style. The effect size for the Mann Whitney U test was then calculated. To analyze the dependence between the nominal data, the non-parametric Chi Square Test of Independence was used, and Cramer's $\mathrm{V}$ was used to determine the strength of association between the variables.
\end{abstract}

Keywords: decision-making styles, well-structured and ill-structured decision problems, decision-making process, decision-making

JEL Classification: M1, M12, M54

Received: June, 2018

1st Revision: November, 2018

Accepted: January, 2019 


\section{INTRODUCTION}

The theory of expected utility, which became well-known and popular in the second half of the 20th century, represents the normative direction in decision-making, emphasizes the rationality of the decision-maker as a phenomenon that recognizes all available solution variants along with consequences, and chooses the variant with the highest utility (Simon, 1979; Wells \& Chiang, 2017). This rationality model does not take into account many conditions and factors in which the actual decision-making in an organization takes place (Sanchez \& Contreras, 2016). The abilities, knowledge and information of the decision-maker are always to a certain extent limited in any decision-making process. Considering a greater number of criteria and the qualitative nature of some of these standards complicates the process of creating and evaluating variants, and thus the selection of decision-making tools. This created a new direction in decision-making theory, the descriptive approach, in which researchers have focused on examining in personal terms the relationships in decision-making in terms of other factors influencing the process, i.e. values, not rushing toward a decision, the degree of certainty, intuition, decision-making style, quality and accessibility of information, crisis and conflict, as well as emotional intelligence (Dubrin, 2011; Seo \& Barrett, 2007; Staňková et. al, 2017) and age (Sproten et al., 2018). According to Ballová-Mikušková (2017), decision-making is influenced by contextual factors such as the environment, time, and type of task. Delcroix et al. (2013) discuss decision problem structuring based on a model that takes into account decision-maker characteristics, contextual characteristics as well as the needs and preferences of all involved. According to Dewberry et al. (2013), decision-making competence can be associated with certain decision-making styles, whereby decision-making styles and personality account for a substantial amount of variance in decision-making competence.

\section{LITERATURE REVIEW}

\subsection{Decision-Making Style}

Decision-making style can be considered a result of the cognitive process leading to the selection of solutions out of several alternatives (Verma, 2009). It represents the manner in which the manager acquires and processes, and how it is used in the decision-making process. Personality is one of the determining indicators of a decision-making style (Garcia-Gallego et al., 2017; Wang et al., 2017) and is based on the theory of personality, i.e. on the assumption that the behavior of an individual influences the way he/she thinks, perceives and evaluates the surrounding environment (Martin, 1997). A study by Raiz et al. (2012) on the influence of personality types on decision-making style has demonstrated that extroversion positively predicts an intuitive and spontaneous decision-making style, while the "inclination to experiment" parameter predicts the intuitive style. A particular decision-making style emerges as two different activities, the first being a decision about the status of the matter to be achieved, and the second how this projected status is to be achieved. Mintzberg \& Westley (2001) understand the decision-making style in terms of the type of decision-maker determined by his/her thinking. Based on the thinking approach, they defined three types of decision-makers - empirical, rational and intuitive. Behaviorists have labeled these individual patterns of interpreting and responding to decisional tasks as 
a decision-making style (Driver et al., 2006). Driver et al. have also demonstrated that decisionmaking styles and the decision-making profile of a senior manager are largely in contrast with the decision-making style of head managers at the basic management level.

Recent research studies dealing with the issues of decision-making style have proven that no manager has only one style. Generally, managers use their own mix, i.e. a combination of at least two styles which can vary depending on the decision-making situation (character and difficulty) (Arroba, 2007), stress or cultural differences. In 2011, Australian researchers conducted a research study in which they investigated cultural differences in decision-making styles using a conflict model of decision-making built on the idea of the ability to effectively manage stress and its impact on the adopted style of decision-making. The following styles were identified - vigilant, hyper-vigilant, avoidant, procrastinative. The researchers discovered that, aside from the "vigilant" style, all decision styles are influenced by psychological fear and anxiety (Brown et al., 2011). The "thinking" personality type positively correlates with the directive style of decision-making, but negatively with the behavioral style. The analytical style of decision-making depends on the "decisive" personality type, while the "perceptive" type negatively correlates with this decision-making style (Ambrien, et.al, 2012). An "intuitive" personality is inclined to adapt the conceptual style of decision-making. The results showed that intuitive personality type showed a significant correlation to the conceptual decision style. Another research study reveals the relationship between the five decision styles (rational, avoidant, intuitive, spontaneous and dependent), and rationality and indecisiveness in decision-making. The rational style of decisionmaking positively predicts the rationality in the decision-making process and negatively predicts the indecision, while an avoidant style positively predicts the indecisiveness (Curşeu \& Schruijer, 2012). Thunholm discovered the degree to which increasing stress levels influence the decisionmaking style (Thunholm, 2008), or whether the decision-making style can indicate depressive symptoms (Leykin \& Derubeis, 2010). Indecisiveness has been proven to be a basic indicator of depression. While the rational and intuitive styles stem from the cognitive styles of gaining and processing information, the conceptual origin of the avoidant, dependent and spontaneous styles is unclear. These styles are accompanied by increased negative stress. The results of the study also demonstrated that decision-makers with the tendency to avoid a decision whenever possible faced an increased level of stress.

Cultural differences in decision-making styles have so far been explored only on a national level or within a certain region. A comparison between Western (represented by the United States, Australia and New Zealand) and Eastern culture (represented by Japan, Hong Kong, China, Thailand) has demonstrated that the vigilant style of decision-making is unchangeable in terms of culture (Mann et al., 1998). Chinese respondents achieved high scores in the "hyper-vigilant" style. The use of decision-making styles in Hispanic countries in addressing social issues has been monitored by researchers in relation to the five dimensions of addressing social problems: positive, negative, rational, impulsive and the avoidance orientation of problem-solving (Morera et al., 2006). The negative orientation toward problem-solving is a strong indicator of the regretbased decision-making style, while respondents with high scores in the impulsive orientation of problem-solving achieve a very low result in the regret-based decision-making style. 


\subsection{Types of Decision-Making Problems}

The essence of the entire decision-making process is to find an appropriate solution to a particular decision-making problem. In terms of complexity and the possibilities of algorithmization, the theory of decision-making differentiates well- and ill-structured decision-making problems, categories between which there are clear differences requiring different cognitive abilities and partial skills of the decision-maker (Namsoo et al., 2003). Decision problems also require a deep monitoring of the current environment conditions (Pérez et al., 2018). Well-structured decision-making problems are characterized by their uniqueness, i.e. each problem has a clear solution with its own procedure, algorithm and clear methodology (Davies, 2000). Well-structured problems represent limited difficulties with convergent solutions for which a limited number of rules and principles within well-defined parameters can be applied. This type of decision problems can be represented by a situation consisting of well-defined initial and target statuses connected by specific steps. Well-structured problems require a certain level of cognition, including domain-specific awareness and structural knowledge related to the problem. The initial planning of a decision-making process can also increase the level of performance in the solving of simple, well-structured problems (Davies, 2003). In increasing complexity and transitioning to ill-structured decision-making problems, initial planning does not greatly affect the decisionmaking process.

Ill-structured decision-making problems have a unique nature, they are open, divergent, and have multiple solution methods, as in being well-structured (Laxman, 2012; Gilbert et al., 2010). This type of decision problem is typical for a complex environment under uncertainty, where concepts and rules and their mutual organization dominate. Ill-structured decision-making problems require a higher level of cognitive thinking (Laxman, 2013; Jackson et al., 2017), the ability to regulate it, epistemic knowledge, and non-cognitive variables. Some cognitive abilities may act as the partial replacement of experience. These abilities have the potential to increase the performance of professionals by helping them synthesize and improve the use of experience with limited knowledge or specific tasks (Wray, 2009; Collins et al., 2016). Wray, similar to Laxman, speaks of a higher level of cognitive abilities.

\section{METHODOLOGY}

The objective of the exploratory research study is to identify the decision-making style of managers in leading positions in Slovak enterprises and monitoring their dependence on the preference of the type of a decision-making problem. To be more precise, the research paper deals with the relationship between the decision-making style of a manager and the type of decision-making problems. The original research sample $(\mathrm{N}=268)$ consists of leading managers working in enterprises in the Slovak Republic in senior and top management positions. The researchers have ensured the measurement objectivity by using data collection tools in electronic form to prevent influencing the research subject. The participants were instructed in writing by one researcher. The observation survey was conducted using a questionnaire on the decision-making of managers. Random sampling was completed as part of computer analysis in PSPP as "approximately $50 \%$ of all cases". 
To identify the decision-making styles, a test based on the MBTI (Myers-Briggs type indicator) was used, observing two dichotomies (sensing/intuiting, thinking/feeling). The purpose of the test is to identify how the manager is acquiring, processing information, and how it is used in the decision-making process. (Myers \& Myers, 2010).

Tab. 1 - Perception of Information and Decision-Making. Source: Rojas (2008)

\begin{tabular}{|l|l|l|l|}
\hline Perception/acquisition of information & Decision-making \\
\hline Sensing & Intuiting & Thinking & Feeling \\
\hline $\begin{array}{l}\text { Perception } \\
\text { favors clear, } \\
\text { specific data } \\
\text { and informa- } \\
\text { tion }\end{array}$ & $\begin{array}{l}\text { Perception favors } \\
\text { abstract concepts, rep- } \\
\text { resenting possibilities of } \\
\text { being inventive }\end{array}$ & $\begin{array}{l}\text { The decision-making } \\
\text { process occurs in objec- } \\
\text { tive conditions, through } \\
\text { logical and analytical } \\
\text { methods }\end{array}$ & $\begin{array}{l}\text { The decision-mak- } \\
\text { ing process occurs } \\
\text { through an intuitive, } \\
\text { sensory method that } \\
\text { focuses on harmony } \\
\text { and value }\end{array}$ \\
\hline
\end{tabular}

The reason for using the MBTI (Myers-Briggs type indicator) was its high reliability and the two-dimensionality of the style rating. For comparison, we present the correlation coefficient and the number of styles of the most often tests used in the following table.

Tab. 2 - Reliability Testing and Number of Style Dimensions. Source: Ambrien et al. (2012)

\begin{tabular}{|l|l|l|l|}
\hline & $\begin{array}{l}\text { Reliability of } \\
\text { the test }\end{array}$ & $\begin{array}{l}\text { Number of } \\
\text { questions }\end{array}$ & $\begin{array}{l}\text { Number of style } \\
\text { dimensions }\end{array}$ \\
\hline DSI (Decision style inventori) & 0.70 & 20 & 2 \\
\hline MBTI(Myers-Briggs type indicator) & 0.84 & 31 & 2 \\
\hline CSI (Consumer styles inventory) & 0.83 & 25 & 1 \\
\hline GDMS (General decision making style) & 0.8 & 25 & 1 \\
\hline
\end{tabular}

The Cronbach's alpha $(\alpha)$ was used to analyze the reliability of the decision-making style test among Slovak managers. Reliability scale Intuitive $\alpha=0.85$. Reliability of individual questions ranging from $\alpha=0.84$ to $\alpha=0.85$. Reliability scale Sensing $\alpha=0.86$. Reliability of individual questions ranging from $\alpha=0.85$ to $\alpha=0.86$. Reliability scale Thinking $\alpha=0.83$. The reliability of individual questions ranging from $\alpha=0.82$ to $\alpha=0.83$. Reliability scale Feeling $\alpha=0.83$. The reliability of individual questions ranging from $\alpha=0.81$ to $\alpha=0.83$. Reliability was tested by omitting several questions. By comparing the reliability values with other authors and testing tools, the values presented here represent an acceptable reliability level of the MBTI test for the decision-making style (Hanák, 2013).

\section{Data Analysis}

Binary logistic regression was used to discover the specific dependence between the independent variable in the nominal form (type of decision problem) and the dependent cardinal variable (the overall score in the decision-making style), thus detecting the measure probabilities of occurrence of the dependent value. 
We observed a systematic divergence in the orientations of managers for well-structured decision-making problems in the variable Decision-making style score. The non-parametric testing of the Mann Whitney $U$ test was used to compare two independent groups. The effect size for the Mann Whitney test was then calculated using the formula (Hanák, 2016):

$\mathrm{r}=\mathrm{Z} / \sqrt{\mathrm{N}}$

The non-parametric Chi Square Test of Independence was used to test the dependence of two nominal variables - Decision-making style (sensing-thinking, sensing-feeling, intuiting-thinking, intuiting-feeling) and Decision-making problem (Well- and Ill-structured) and Cramer's V was used to determine the degree of association between dependent variables (Marek, 2007). The research paper monitors the dependence between the decision-making style and the type of decision-making problem.

The data obtained were analyzed in the PSPP statistical software. Hypotheses were tested at the significance level of $\alpha \leq 0.05$. The primary rule of the use of the test was observed, where the theoretical frequencies did not fall below the value of 5 in $80 \%$, and for other values $\mathrm{X}>1$ applied.

\section{RESULTS}

\section{Decision-Making Style}

Every decision-making style has its own value. The objective of the research was to identify individual decision-making styles of Slovak managers in leading positions. The survey demonstrates that up to $68 \%$ of managers use a Sensing-Thinking style of decision-making. The second most common style used by Slovak managers is the Intuiting-Thinking style (17\%). The least widespread style is Thinking-Feeling (11\%) and Intuiting-Feeling (4\%). The dominant style of Sensing-Thinking decision-making is the following. Sensing style (Myers \& Myers, 2010) focuses on what is real and up-to-date. Its domain is the sequential gathering of information while working systematically. Creativity in a ration type is not common, instead they tend to adapt to a current system. Thinking style (referred to as "systematic" by several authors) uses a logical process that allows managers to target impersonal conclusions and decisions. The manager relies on the "cause and effect" principle.

Tab. 3 - Frequency table for Decision Making Style Score. Source: researchers' own processing

\begin{tabular}{|l|l|l|l|l|l|l|l|l|l|l|l|}
\hline Variable & $\mathrm{N}$ & Mean & $\begin{array}{l}\text { Std } \\
\text { Dev }\end{array}$ & $\begin{array}{l}\text { Vari- } \\
\text { ance }\end{array}$ & $\begin{array}{l}\text { Kur- } \\
\text { tosis }\end{array}$ & $\begin{array}{l}\text { S.E. } \\
\text { Kurt }\end{array}$ & $\begin{array}{l}\text { Skew- } \\
\text { ness }\end{array}$ & $\begin{array}{l}\text { S.E. } \\
\text { Skew }\end{array}$ & Range & Min. & Max. \\
\hline Intuiting & 268 & 10.56 & 5.90 & 34.79 & -.29 & .30 & .54 & .15 & 27.00 & .00 & 27.00 \\
\hline Sensing & 268 & 20.27 & 5.98 & 35.71 & -.35 & .30 & -.53 & .15 & 27.00 & 4.00 & 31.00 \\
\hline Thinking & 268 & 20.98 & 5.39 & 29.03 & .32 & .30 & -.71 & .15 & 30.00 & 1.00 & 31.00 \\
\hline Feeling & 268 & 9.87 & 5.37 & 28.79 & .32 & .30 & .72 & .15 & 30.00 & .00 & 30.00 \\
\hline
\end{tabular}

Based on the results from the frequency table, we can say that the respondents are more sensing $(M=20.27)$ than intuiting $(M=10.56)$. This result refers to a style how people obtain information for decision-making. In the sub-style method of processing information for decision- 
making, respondents are more analytical $(M=20.98)$ than having the feeling style $(M=9.87)$. Simultaneously, the rating of individual styles in the sensing scale was more variable ( $\mathrm{SD}=5.98)$ compared to the response scale in the intuiting $(\mathrm{SD}=5.90)$. The difference in variability in the thinking $(\mathrm{SD}=5.39)$ and feeling $(\mathrm{SD}=5.37)$ score was minimal. The distribution normality was monitored through kurtosis and skewness. Based on the kurtosis data for the intuiting (kurtosis $=-29$ ) and sensing (kurtosis $=-35$ ) scales, it is a more even distribution compared to the normal division. On the thinking (kurtosis $=.32$ ) and feeling (kurtosis $=.32$ ) scale, the values are higher than average. The skewness also points to the non-normal distribution of data in the decisionmaking style set - the right skewness of the thinking (skewness $=-.71$ ) and sensing (skewness $=-.53$ ) score confirming the high point scores achieved in the test. Conversely, skewness of the intuiting (skewness $=.54$ ) and feeling (skewness $=.72$ ) score are on the left, i.e. low point responses.

\section{Decision-Making Style and Decision-Making Problem}

The decision-making problem and the manager's approach to its solution (rational and intuitive) are basic elements of decision-making. The decision-making problem solved by two managers with different decision-making styles influences the entire decision-making process and its result. Kathri and his team confirmed that intuitive syntheses have a positive relationship to organizational performance in an unstable environment. Conversely, using intuition in a stable environment has very negative effects, the reason for the key significance between the performance of the organization and the use of Intuitive decision-making. The above-mentioned research was the inspiration of the knowledge for researching the relationship of the decisionmaking style and the type of a decision-making problem (Kathri, 2000). We tried to find out whether the decision-making style is associated with the preferred type of a decision-making problem. The objective was to monitor which type of a problem (task) is characteristic of each decision-making style. We did not study the real distribution of types of problems in the work of managers. Therefore, the following question was asked in the gathering of data: "What type of problem-solving or task-solving suits you more?" The following hypotheses were tested:

$\mathrm{H} 0=$ there is no dependence between the decision-making style of the manager and the type of a decision problem.

$\mathrm{H} 1=$ the decision-making style and type of decision problem are related to one another

Tab. 4 - Chi-squared test: Decision-Making style * Type of Decision-Making problem. Source: researchers' own processing

\begin{tabular}{|l|l|l|l|l|l|}
\hline Category & Statistic & Value & $\begin{array}{l}\text { Asymp. Std. } \\
\text { Error }\end{array}$ & Approx. T & Approx. Sig. \\
\hline $\begin{array}{l}\text { Nominal by } \\
\text { Nominal }\end{array}$ & Phi & .38 & & & \\
\hline $\begin{array}{l}\text { N of Valid } \\
\text { Cases }\end{array}$ & Cramer's V & .38 & & & \\
\hline
\end{tabular}


The null hypothesis was rejected at the significance level of $\mathrm{p} \leq 0.01$, as there is a very strong evidence of dependence among the studied variables ( $\mathrm{p}$-value $<0.01,=37.75, \mathrm{df}=3$ ), whereas the Decision-Making Style and Decision-Making Problem have a moderately strong dependence $(\mathrm{V}=0.38)$.

Managers with an Intuiting decision-making style prefer ill-structured decision-making problems. Conversely, a Sensing style favors well-structured problems. The largest category of decision-making styles regarding Slovak managers is the Sensing-Thinking decision-making style (Procházková \& Remeňová, 2014). Nearly 75\% of managers prefer to solve well-structured problems (tasks) within this category. This type of task also favors a Sensing-Feeling style of decision-making. Ill-structured tasks are favored by managers in an Intuiting-Thinkig style $(70 \%$ of managers) and Intuiting-Feeling style ( $72 \%$ of managers). Similar results were also achieved by other researchers (Mintzberg \& Westley, 2001; Verma et al., 2016; Scott \& Bruce, 1995; Spicer \& Sadler-Smith, 2005), who confirmed that the Sensing style is often used in well-structured decision-making problems.

In the binary logistic regression, we observed the dependence between the decision-making style score and the decision-making problem. We were interested in whether the achieved score in the decision-making style test can predict the manager's focus on solving well-structured decisionmaking problems or ill- structured problems. The following hypotheses were tested:

H1: The score in the decision-making style (sensing, intuiting, feeling, thinking) predicts the manager's orientation toward solving well- or ill-structured decision-making problems

H0: The score in the decision-making style does not affect the orientation of the manager toward solving well- or ill- structured decision-making problems.

Tab. 5 - Model Summary for Sensing and Decision Problem. Source: researchers' own processing

\begin{tabular}{|l|l|l|l|}
\hline Step 1 & -2 Log likelihood & Cox \& Snell R Square & Nagelkerke R Square \\
\hline & 304.21 & .17 & .23 \\
\hline
\end{tabular}

\begin{tabular}{|c|c|c|c|c|c|c|c|c|c|}
\hline & & \multirow[t]{2}{*}{ B } & \multirow[t]{2}{*}{ S.E. } & \multirow[t]{2}{*}{ Wald } & \multirow[t]{2}{*}{ df } & \multirow[t]{2}{*}{ Sig. } & \multirow[t]{2}{*}{$\operatorname{Exp}(B)$} & \multicolumn{2}{|c|}{$\begin{array}{l}95 \% \text { CI for } \\
\operatorname{Exp}(B)\end{array}$} \\
\hline & & & & & & & & Lower & Upper \\
\hline \multirow{2}{*}{ Step 1} & Sensing & -.16 & .03 & 39.33 & 1 & .000 & .85 & .81 & .89 \\
\hline & Constant & 2.68 & .52 & 26.16 & 1 & .000 & 14.54 & & \\
\hline
\end{tabular}

In the model description table (Table 5), the result of the size of the variance in the orientation on well- or ill-structured decision-making problems depends on the score in the Sensing decisionmaking style. From the data, we can see that the $23 \%$ variance in the orientation on the type of a decision problem depends on the score in the decision-making style test. The Wald coefficient $(z=39.33)$ indicates whether the $b$ coefficient $(b=-.16)$ for the predictor (Sensing) is statistically significantly different from zero $(\mathrm{p}<.001)$. Exp (B) talks about increasing the odds ratio when increasing the predictor value by the unit. Based on the results, we rejected the alternative $\mathrm{H} 1$ hypothesis and accepted null hypothesis $\mathrm{H} 0$ since the odds ratio of being in a group of well- or 
ill-structured problems in increasing the predictor - the score for the Sensing decision-making style, does not grow Exp $(B)=.85$. Thus, the change in the number of score in the Sensing decision-making style has no effect on the inclusion in an ill- structured group.

Tab. 6 - Model Summary for Intuiting and Decision-Making Problem. Source: researchers' own processing

\begin{tabular}{|l|l|l|l|}
\hline \multirow{2}{*}{ Step 1 } & -2 Log likelihood & Cox \& Snell R Square & Nagelkerke R Square \\
\cline { 2 - 4 } & 302.33 & .17 & .24 \\
\hline
\end{tabular}

\begin{tabular}{|l|l|l|l|l|l|l|l|l|l|}
\hline & & & S.E. & Wald & df & Sig. & $\operatorname{Exp}(B)$ & \multicolumn{2}{|l|}{$95 \%$ CI for $\operatorname{Exp}(\mathrm{B})$} \\
\cline { 4 - 11 } & & & & & & & Lower & Upper \\
\hline \multirow{2}{*}{ Step 1 } & Intuiting & .17 & .03 & 40.32 & 1 & .000 & 1.18 & 1.12 & 1.25 \\
\cline { 2 - 11 } & Constant & -2.41 & .33 & 52.15 & 1 & .000 & .09 & & \\
\hline
\end{tabular}

Nagelkerke R Square (.24) presents a $24 \%$ variation in inclusion of managers in the group of illstructured decision-making problems depending on the score in the Intuiting decision-making style. Simultaneously, Wald $(z=40.32)$ and the $b$ coefficient for the Intuiting predictor $(b=.17)$ is statistically significantly different from zero $(p$ <.001). $\operatorname{Exp}(B)=1.18$ talks about increasing the odds ratio of an event by increasing the predictor value by a unit. Based on the above-stated result, we accepted the alternative H1 hypothesis. If we increase the Intuiting score by a unit, the odds ratio in the group of ill-structured decision-making problems increases.

Tab. 7 - Model Summary for Thinking and Decision-Making Problem. Source: researchers' own processing

\begin{tabular}{|l|l|l|l|}
\hline \multirow{2}{*}{ Step 1 } & $-2 \log$ likelihood & Cox \& Snell R Square & Nagelkerke R Square \\
\cline { 2 - 4 } & 350.35 & .01 & .01 \\
\hline
\end{tabular}

\begin{tabular}{|l|l|l|l|l|l|l|l|l|l|}
\hline & & & S.E. & Wald & df & Sig. & Exp(B) & \multicolumn{2}{|l|}{$95 \%$ CI for $\operatorname{Exp}(\mathrm{B})$} \\
\cline { 5 - 11 } & & & & & & & Lower & Upper \\
\hline \multirow{2}{*}{ Step 1 } & Thinking & -.04 & .02 & 2.67 & 1 & .102 & .96 & .92 & 1.01 \\
\cline { 3 - 11 } & Constant & .26 & .26 & .28 & 1 & .599 & 1.30 & & \\
\hline
\end{tabular}

Nagelkerke R Square (.01) presents only a $1 \%$ variation in inclusion of managers in the group of well- or ill-structured decision-making problems depending on the number of points in the Thinking decision-making style. While the Wald $z=2.67$ and $b$ the coefficient $(b=-.04)$ for the Thinking predictor is not statistically significantly different from zero ( $p>1$. . . Based on the above-stated results, we accepted the null $\mathrm{H} 0$ hypothesis. If we increase the Thinking score by a unit, the odds ratio in the group of ill-structured decision-making problems does not increase. 
Tab. 8 - Model Summary for Feeling and Decision-Making Problems. Source: researchers' own processing

\begin{tabular}{|l|l|l|l|}
\hline \multirow{2}{*}{ Step 1 } & -2 Log likelihood & Cox \& Snell R Square & Nagelkerke R Square \\
\cline { 2 - 4 } & 350.57 & .01 & .01 \\
\hline
\end{tabular}

\begin{tabular}{|l|l|l|l|l|l|l|l|l|l|}
\hline \multicolumn{2}{|c|}{} & \multirow{2}{*}{ B } & S.E. & \multirow{2}{*}{ Wald } & \multirow{2}{*}{ df } & \multirow{2}{*}{ Sig. } & \multirow{2}{*}{ Exp(B) } & \multicolumn{2}{l|}{$\begin{array}{l}\text { 95\% CI for } \\
\text { Exp(B) }\end{array}$} \\
\hline \multirow{2}{*}{ Step 1 } & & & & & & & Lower & Upper \\
\cline { 2 - 11 } & Ceeling & .04 & .02 & 2.45 & 1 & .118 & 1.04 & .99 & 1.09 \\
\hline
\end{tabular}

Nagelkerke R Square (.01) presents only a $1 \%$ variation in inclusion of managers in the group of well- or badly-structured decision-making problems depending on the number of points in the Feeling decision-making style. While the Wald $z=2.45$ and the $b$ coefficient $(b=-.04)$ for the Feeling predictor is not statistically significantly different from zero ( $p>$.1). Based on the above-stated result, we accepted the null hypothesis. If we increase the Feeling score by a unit, the odds ratio in the group of ill-structured decision-making problems may increase Exp $(B)=1.04$, but this result is not statistically significant $\mathrm{p}=.118$. Based on the results of binary logistic regression, we can say that of the four decision styles, the preference of selecting the ill-structured decision-making problems can be only predicted by the Intuiting $(\operatorname{Exp}(B)=1.18)$ decision-making style.

Systematic differences in the orientation on well- and ill-structured decision-making problems were analyzed through the non-parametric testing of the Mann Whitney $U$ test. The selection of the used test was conditional on the fulfillment of conditions for the use of parametric tests. The variable on which the two groups were compared is interval. Simultaneously, the measurement independence was ensured as described in the research design. The data distribution normality was tested through the Kolmogorov-Smirnov test.

Tab. 9 - Kolmogorov-Smirnov Test for Decision-Making Style Score. Source: researchers' own processing

\begin{tabular}{|l|l|l|l|l|l|}
\hline & & Intuiting & Sensing & Thinking & Feeling \\
\hline $\mathrm{N}$ & & 268 & 268 & 268 & 268 \\
\hline Normal Parameters & Mean & 10.56 & 20.27 & 20.98 & 9.87 \\
\hline & Std. Dev. & 5.90 & 5.98 & 5.39 & 5.37 \\
\hline Most Extreme Differences & Absolute & .09 & .09 & .09 & .10 \\
\hline & Positive & .09 & .06 & .05 & .10 \\
\hline & Negative & -.05 & -.09 & -.09 & -.05 \\
\hline Kolmogorov-Smirnov Z & & 1.41 & 1.41 & 1.55 & 1.62 \\
\hline Asymp. Sig. (2-tailed) & & .027 & .026 & .010 & .007 \\
\hline
\end{tabular}


The significance level $\mathrm{p}$ for all decision styles is lower than .05, meaning that the results of the test are statistically significant, thus the assumption of a normally distributed data is disrupted. The results of the Levene's test for analyzing the sphericity and homogeneity of variance confirm the violation of this assumption, as $\mathrm{p}=.035$.

Since both tests confirmed the violation of conditions for parametric testing, we used the nonparametric Mann Whitney U test to compare the two groups. We were interested in whether managers who prefer to solve well-structured decision-making problems achieve a statistically significantly higher score in the Sensing and Thinking style than managers who prefer ill-structured decision-making problems. The following hypotheses were tested:

H1: Managers who prefer well-structured decision-making problems reach a statistically significantly higher score in the Sensing and Thinking decision making style than managers who prefer ill-structured decision-making problems.

H0: There is no statistically significant difference between the two groups (well- or ill-structured problems) in decision-making style score.

Tab. 10 - Ranks and Test Statistics for Sensing Score. Source: researchers' own processing

\begin{tabular}{|l|l|l|l|l|l|l|l|}
\hline \multirow{2}{*}{ Ranks } & \multicolumn{2}{|l|}{ N } & \multicolumn{2}{l|}{ Mean Rank } & \multicolumn{2}{l|}{ Sum of Ranks } \\
\cline { 2 - 9 } & 1 & 2 & Total & 1 & 2 & 1 & 2 \\
\hline Sensing Score & 85.00 & 49.00 & 134.00 & 158.89 & 92.86 & 26852.50 & 9193.50 \\
\hline
\end{tabular}

\begin{tabular}{|l|l|l|l|l|}
\hline & Mann-Whitney U & Wilcoxon W & Z & Asymp. Sig. (2-tailed) \\
\hline Sensing Score & 4243.50 & 9193.50 & -6.74 & .000 \\
\hline
\end{tabular}

On average, the Manger Group 2 received fewer points in the Sensing decision-making style than Group 1, i.e. those managers who prefer well-structured decision-making problems. The Mean Rank for Group 1 is statistically significantly higher than for Group 2. Based on the results of non-parametric testing, we reject the null hypothesis and accept the alternative H1 hypothesis since the preference of a well-structured decision-making problem had a statistically significant $(p<.001)$ effect on the amount of points achieved in the Sensing style. The effect size for the Sensing variable is $r=-.4117$, explaining the variability of $17 \%$.

Tab. 11 - Ranks and Test Statistics for Intuiting Score. Source: researchers' own processing

\begin{tabular}{|l|l|l|l|l|l|l|l|}
\hline \multirow{2}{*}{ Ranks } & \multicolumn{3}{|l|}{ N } & \multicolumn{3}{l|}{ Mean Rank } & \multicolumn{2}{l|}{ Sum of Ranks } \\
\cline { 2 - 9 } & 1 & 2 & Total & 1 & 2 & 1 & 2 \\
\hline Intuiting Score & 85.00 & 49.00 & 134.00 & 109.81 & 176.65 & 18557.50 & 17488.50 \\
\hline
\end{tabular}

\begin{tabular}{|l|l|l|l|l|}
\hline & Mann-Whitney U & Wilcoxon W & $\mathrm{Z}$ & Asymp. Sig. (2-tailed) \\
\hline Intuiting Score & 4192.50 & 18557.50 & -6.82 & .000 \\
\hline
\end{tabular}

On average, managers who prefer ill-structured decision-making problems scored more points in the Intuiting decision-making style than Group 1 (managers who prefer well-structured decision-making). The Mean Rank for Group 2 is statistically significantly higher than for Group 
$1(\mathrm{p}<.001)$. Based on the results, we accept the alternative H1 hypothesis since the preference of ill-structured decision-making problems has a statistically significant effect $(p<.001)$ on the amount of the Intuiting points. The effect size for the Intuiting variable is $r=-.4166$, explaining the variability of $17.3 \%$.

Tab. 12 - Ranks and Test Statistics for Thinking Score. Source: researchers' own processing

\begin{tabular}{|l|l|l|l|l|l|l|l|}
\hline \multirow{2}{*}{ Ranks } & \multicolumn{3}{|l|}{ N } & \multicolumn{2}{l|}{ Mean Rank } & \multicolumn{2}{l|}{ Sum of Ranks } \\
\cline { 2 - 9 } & 1 & 2 & Total & 1 & 2 & 1 & 2 \\
\hline Thinking Score & 85.00 & 49.00 & 134.00 & 140.05 & 125.03 & 23668.00 & 12378.00 \\
\hline
\end{tabular}

\begin{tabular}{|l|l|l|l|l|}
\hline & Mann-Whitney U & Wilcoxon W & Z & Asymp. Sig. (2-tailed) \\
\hline Thinking Score & 7428.00 & 12378.00 & $-1.53 \%$ & .125 \\
\hline
\end{tabular}

On average, the group of managers who prefer well-structured decision-making problems scored more points in the Thinking decision-making style than Group 2 (managers who prefer ill-structured decision-making). However, the difference in the Mean Rank of $\mathrm{p}=.125$ is not statistically significantly higher for Group 1. Based on the results of the non-parametric testing, we reject the alternative $\mathrm{H} 1$ hypothesis and accept the null $\mathrm{H} 0$ hypothesis. The preference of a well-structured decision-making problem had no statistically significant effect on the amount of the points achieved in the Thinking style (the effect size for the Thinking $r=-.0935$, not explaining variability by even one percent).

Tab. 13 - Ranks and Test Statistics for Feeling Score. Source: researchers' own processing

\begin{tabular}{|l|l|l|l|l|l|l|l|}
\hline \multirow{2}{*}{ Ranks } & \multicolumn{3}{|l|}{ N } & \multicolumn{2}{l|}{ Mean Rank } & \multicolumn{2}{l|}{ Sum of Ranks } \\
\cline { 2 - 9 } & 1 & 2 & Total & 1 & 2 & 1 & 2 \\
\hline Feeling Score & 85.00 & 49.00 & 134.00 & 129.33 & 143.33 & 21856.50 & 14189.50 \\
\hline
\end{tabular}

\begin{tabular}{|l|l|l|l|l|}
\hline & Mann-Whitney U & Wilcoxon W & Z & Asymp. Sig. (2-tailed) \\
\hline Feeling Score & 7491.50 & 21856.50 & -1.43 & .153 \\
\hline
\end{tabular}

Managers who prefer ill-structured decision-making problems scored more points in the Feeling decision-making style than Group 1 (managers who prefer well-structured decision-making). However, the Mean Rank of $\mathrm{p}=.153$ for Group 2 is not statistically significantly higher than for Group 1. Based on the results of the non-parametric testing, we reject the alternative H1 hypothesis and accept the null $\mathrm{H} 0$ hypothesis since the preference of ill-structured decision-making problems did not have a statistically significant effect on the amount of the points achieved in the Feeling style. The effect size for the Feeling variable is $r=-.087$, not explaining variability by even one percent.

\section{DISCUSSION AND CONCLUSION}

An understanding of decision-making styles can provide great insight into how information is obtained, processed, and, finally, used in the decision-making process. The objective of this re- 
search was to identify individual decision-making styles of Slovak managers and the relationship between the decision-making style of a manager and the preference of the type of decision-making problems. Our research brings together two fundamental and interrelated aspects of competent decision-making: decision-making style and the specific type of decision problem.

Our survey demonstrates that up to $68 \%$ of managers use the Sensing-Thinking style of decision-making, followed by the Intuiting-Thinking style (17\%). The least widespread style is the Sensing-Feeling (11\%) and Intuiting-Feeling style (4\%). The Sensing style decision-maker favors well-structured decision-making tasks, i.e. those for which a clear method or methodology of solution exists. The Intuiting style decision-maker favors ill-structured decision-making tasks, i.e. those for which the solution has no clear procedure or methodology. This decision-maker searches for alternative methods of problem solving using his/her intuition.

Based on the research results, only the Intuitive decision-making style can predict the preference for ill-structured decision problems. Only in the Sensing style was the assumption confirmed that managers who prefer handling well-structured decision-making problems achieve a statistically significantly higher score in the Sensing and Thinking decision-making style than managers who prefer ill-structured decision-making problems. Team leaders who prefer ill-structured decision problems reached a higher score in the Intuiting decision-making style.

Our research outcome also confirmed a low use of the Intuiting decision-making style as compared to the Sensing style. The as yet unexplored phenomenon of Intuitive decision-making is slowly gaining currency with Slovak managers. However, the professional literature still has not produced any coherent and unified way of using the Intuiting decision-making style in practice.

Our research provides additional profound insights into how team leaders can increase the efficiency and accuracy of decisions. If knowledge of decision-making styles concerning the manager's preferences to address well-structured or ill-structured decision-making problems was used in top management, the company itself could create long-term added value in the form of stable competitiveness.

Previous knowledge regarding decision-making styles along with their use with specific issues in terms of well-structured and ill-structured decision problems is helpful when building a team as well as improving their performance; in the establishment of teams through such a method in which individual decision-making styles are mutually supportive, the threat of "group think" can be eliminated. Knowledge of the decision-making style of an employee and a team leader makes it easier for a manager to assign appropriate tasks to individuals and properly redistribute tasks and competences within the team.

\section{Practical implications}

The information presented in this research article is essential to managers at all management levels in terms of the in-depth knowledge of the compatibility of their decision-making style with the styles of their direct subordinates. This knowledge can be seen as a useful tool for delegating tasks which also allows managers to avoid conflicts caused by misunderstanding (or expectations) regarding a task (problem) by a subordinate. Therefore, a strong assumption can be made that an employee with an intuitive decision-making style, in which the conceptual way 
of thinking (impact on the future) dominates and dealing with abstract concepts is preferred, will have difficulty with a well-structured problem. Well-structured problems require specific facts and current information, also a concrete methodology, guidelines, terms, and models. This directly relates to the importance of knowing the decision-maker's style, how he/she obtains information, what kind of reasoning process he/she uses, as well as how he/ she perceives issues and selects essential information for the decision-making process.

\section{Limitation of the study}

Despite the relatively unprecedented nature of our results, we realize the research limitation of testing in a single country. Further, this article focuses on narrow and specific issues of the decision-making problem and the decision-making style of team leaders. As we only tested leading managers, the scope of the research does not cover the knowledge regarding the team decision and the decision-making styles of individual team members. Therefore, further investigations would be necessary. It would also be essential to monitor the relationship between the effectiveness of the team decisions and whether or not the preference of the type of decision problem can predict the success or failure to implement a particular decision.

\section{Acknowledgements}

For the financial support to carry out this research, the authors are grateful to VEGA No.: 1/0109/17 Innovative approaches to management and their influence on the competitiveness and the successfulness of the companies within the conditions of the global economy.

\section{References}

1. Ambrien, A., Hasnain, N., \& Venkatesan, M. (2012). Decision making in relation to personality types and cognitive style of business students. The IUP Journal of Management Research, 11 (2), 20-29.

2. Arroba, T. (2007). Styles of decision making and their use: An empirical study. British Journal of Guidance \& Counselling, 5 (2), 149-158. https://doi.org/10.1080/03069887708258110

3. Brown, J., Ssekamanya, S. A., \& NG, R. (2011). Decision making style East and West: is it time to move beyond cross-cultural research? International Journal of Sociology and Anthropology, 3 (2), 452-459. https://dx.doi.org/10.5897/IJSA

4. Collins, R. H., Sibthorp, J., \& Gookin, J. (2016). Developing Ill-Structured ProblemSolving Skills through Wilderness Education. Journal of Experiential Education, 39 (2), 179-195. https://doi.org/10.1177/1053825916639611

5. Curşeu, P. L., \& Schruijer, S. G. L. (2012). Decision making style and rationality: An analysis of the predictive validity of the general decision making style inventory. Educational \& Psychological Measurement, 72 (6), 1053-1062.

6. Davies, S. (2000). Memory and planning processes in solutions to well-structured problems. Quarterly Journal of Experimental Psychology: Section A, 53 (3), 896-927. http://dx.doi. org $/ 10.1080 / 713755943$

7. Davies, S. (2003). Initial and concurrent planning in solutions to well-structured problems. Quarterly Journal of Experimental Psychology: Section A, 56 (7), 1147-1164. http://dx.doi. $\operatorname{org} / 10.1080 / 02724980245000061$ 
8. Delcroix, V., Sedki, K., \& Lepoutre, F-X. (2013). A Bayesian network for recurrent multicriteria and multi-attribute decision problems: Choosing a manual wheelchair. Expert Systems with Applications, 40 (7), 2541-2551. https://doi.org/10.1016/j.eswa.2012.10.065

9. Dewberry, C., Juanchich, M., \& Narendran, S. (2013). Decision-making competence in everyday life: The roles of general cognitive styles, decision-making styles and personality. Personality and individual differences, 55(7), 783-788. https://doi.org/10.1016/ j.paid.2013.06.012

10. Driver, M. J., Brousseau, K. R., Hourihan, G., \& Larsson, R. (2006). The seasoned executive's decision-making style. Harvard Business Review, 84 (2), 110-121.

11. Dubrin, A. (2011). Essentials of management. Hampsire: Cengage learning.

12. Garcia-Gallego, A., Ibanez, M. I., \& Georgantzis, N. (2017). Editorial: Personality and Cognition in Economic Decision Making. Frontiers in Psychology, 8, 848. https://doi. org/10.3389/fpsyg.2017.00848

13. Gilbert, S., Zamenopoulos, T., Alexiou, K., \& Johnson, J. H. (2010). Involvement of right dorsolateral prefrontal cortex in ill-structured design cognition: An fMRI study. Brain Research, 1312 (2), 79-88. http://dx.doi.org/10.1016/j.brainres.2009.11.045

14. Hanák, R. (2016). Dátová analýza pre sociálne vedy. Bratislava: Ekonóm.

15. Hanák, R., Ballová Mikušová, E., \& Čavojová, V. (2013). Roz̧̧odovanie a usudzৃovanie IV. Aplikácie a limity intuície. Bratislava: Ústav experimentálnej psychológie.

16. Jackson, S. A., Kleitman, S., Stankov, L., \& Howie, P. (2017). Individual Differences in Decision Making Depend on Cognitive Abilities, Monitoring and Control. Journal of Behavioral Decision Making, 30 (2), 209-223. http://dx.doi.org/10.1002/bdm.1939

17. Kathri, N., \& Ng, H.A. (2000). The Role of Intuition in Strategic Decision Making. Human Relations, 53(1), 57-86.

18. Laxman, K. (2012). Cognitive learning processes undergirding design-based ill-structured problem solving. Journal of Innovation and Learning, 11(1), 60-78. http://dx.doi.org/10.1504/ IJIL.2012.044329

19. Laxman, K. (2013). Training students to solve ill-structured problems in an online learning environment. International Journal of Teaching and Case Studies, 4 (2), 143-159. http://dx.doi. org/10.1504/IJTCS.2013.058801

20. Leykin, Y., \& Derubeis, R. (2010). Decision-making styles and depressive symptomalogy: Development of the Decision Styles Questionnaire. Judgment and Decision Making, 5 (7), 506-515.

21. Mann, L., Radford, M., Burnett, P., Ford, S., Bond, M., Leung, K., Nakamura, H., Vaughan, G., \& Yang, K. (1998). Cross-cultural differences in self-reported decision making style and confidence. Journal of Psychology, 33 (5), 325-335. https://doi.org/10.1080/002075998400213

22. Martin, Ch. R. (1997). Looking at type: The fundamentals. Gainesville: Center for Applications of Psychological Type. 
23. Ballová - Mikušková, E. (2017). Intuition in managers' decision-making: qualitative study. Journal for East European Management Studies, 22(3), 318-333. https://doi.org/10.5771/09496181-2017-3-318

24. Mintzberg, H., \& Westley, F. (2001). Decision making: it's not what you think: sometimes decisions defy purely step-by-step logic. To be effective, companies also should embrace intuitive or action-oriented forms of decision making. MIT Sloan Management Review, 42 (3), 89-95.

25. Morera, O. F., Mayeu-Olivares,A., Nygren, T. E., White, R. J., Fernandez, N. P., \& Skewes, M. C. (2006). Social problem solving predicts decision making styles among US Hispanics. Personal and Individual differences, 41 (2), 307-317. https://doi.org/10.1016/j.paid.2005.08.016

26. Myers, I., \& Myers, P. (2010). Gifts Differing: Understanding Personality Type. Reprint. Boston: Nicholas Brealey Publishing.

27. Namsoo S., Jonassen, D.H., \& McGee, S. (2003). Predictors of well-tructured and illstructured problem solving in an astronomy simulation. Journal of Research in Science Teaching, 40 (1), 6-33. https://doi.org/10.1002/tea.10058

28. Pérez, I. J., Cabrerizo, F. J., Alonso, S., Dong, Y. C., Chiclana, F., \& Herrera-Viedma, E. (2018). On dynamic consensus processes in group decision making problems. Information Science, 459 (1), 20-35. https://doi.org/10.1016/j.ins.2018.05.017

29. Procházková, K., \& Remeňová, K. (2014). Roz̧hodovanie manažérov a ich vodcovskéy potenciál. Bratislava: Ekonóm.

30. Raiz, N., Raiz, A. \& Batool, N. (2012). Personality Types as Predictors of Decision Making Styles. Journal of Behavioural Sciences, 22 (2), 99-114.

31. Rojas, E. M. (2008). Construction Productivity: A Practical Guide for Building and Electrical Contractors. Fort Lauderdale: J. Ross Publishing.

32. Sanchez, M. A. M. Contreras, L. E. S. (2016). An economic-institutional perspective of decision making: solving problems in uncertainty contexts. Investigacion Economica, 75(298), $57-75$

33. Scott, S. G., \& Bruce, R. A. (1995). Decision-making style: The development and assessment of a new measure. Educational and Psychological Measurement, 55 (5), 818-831. http://dx.doi.org/10.1177/0013164495055005017

34. Seo, M., \& Barrett, L. F. (2007). Being Emotional during Decision Making: Good or Bad? An Empirical Investigation. The Academy of Management Journal, 50 (4), 923-940. https://doi. org/10.5465/amj.2007.26279217

35. Simon, H. (1979). Rational Decision Making in Business Organizations. The American Economic Review, 69 (4), 493-513.

36. Spicer, D. P., \& Sadler-Smith, E. (2005). An examination of the general decision making style questionnaire in two UK samples. Journal of Managerial Psychology, 20 (2), 137-149. https://doi.org/10.1108/02683940510579777

37. Sproten, A., N., Diener, C., Fiebach, Ch., J., \& Schwieren, Ch. (2018). Decision making and age: Factors influencing decision making under uncertainty. Journal of Behavioral and Experimental Economics, 76, 43-54. https://doi.org/10.1016/j.socec.2018.07.002 
38. Staňková, P., Horkelová, J., Lučzewská J., Tichá J., Zimč́́ková S., \& Černobila J. (2017). The key factors influencing clients'decision-making in the market of selected planned healthcare in the Czech Republic. Journal of Competitiveness, 9(4), 94-113. http://dx.doi.org/10.7441/ joc.2017.04.07

39. Thunholm, P. (2008). Decision-making styles and physiological correlates of negative stress: Is there a relation? Scandinavian Journal of Psychology, 49 (3), 213-219. https://doi. $\operatorname{org} / 10.1111 / \mathrm{j} .1467-9450.2008 .00640 . \mathrm{x}$

40. Verma, D. (2009). Decision Making Style: Social and Creative Dimensions. New Delhi: Global India Publications.

41. Verma, N., Rangnekar, S. N., \& Barua, M. K. (2016). Exploring decision making style as a predictor of team effectiveness. International Journal of Organizational Analysis, 24 (1), 36-63. https://doi.org/10.1108/IJOA-01-2012-0547

42. Wang, X., Pan, Y., Zhang, Sui, Y. J. Lv, T. J. Xu, S. H. Gao, L. (2017). emotional experience and personality traits influence individual and joint risk-based decision making. Social behavior and personality, 45(6), 881-892. https://doi.org/10.2224/sbp.6541

43. Wells, A. R., \& Chiang, K. (2017). Decision Theory: Making It Rational. England: Blackwell science publishing. https://doi.org/10.1002/9781119356271.ch8

44. Wray, E. B. (2009). Ability and Performance on Ill-Structured Problems: The Substitution Effect of Inductive Reasoning Ability. Behavioral Research in Accounting, 21(1), 19-35. http:// dx.doi.org/10.2308/bria.2009.21.1.19

\section{Contact information}

Ing. Katarina Remenova, Ph.D., MBA

University of Economics in Bratislava

Faculty of Business Management

Department of Management

Slovak Republic

E-mail:katarina.remenova@euba.sk

Doc. Ing. Nadezda Jankelova, Ph.D.

University of Economics in Bratislava

Faculty of Business Management

Department of Management

Slovak Republic

E-mail:nadezda.jankelova@euba.sk

ORCID: 0000-0002-0045-4737 